Methods: Included in the study were patients treated with a single intravenous $\mathrm{ZOL}$ infusion $5 \mathrm{mg}$. Exclusion criteria were previous treatment with ZOL, treatments interfering with CTLA-4, and estimated glomerular filtration rate $<35 \mathrm{ml} / \mathrm{min}$. APR was defined as a rise in axillary temperature above $38^{\circ} \mathrm{C}$ at any time during the first 48 hours and an increase in musculoskeletal pain by more than $10 \mathrm{~mm}$ in a visual analogue scale (VAS, from 0 to $100 \mathrm{~mm}$ ). Clinical and laboratory parameters were assessed at baseline, before $\mathrm{ZOL}$, and at 24, 48 and 72 hours after the infusion.

Results: Ten female patients (mean age 73-10 years) were included (2 had vertebral fractures and the remaining had osteoporosis), 5 of whom experienced APR (APR+) associated with the expected increases in serum CRP and IL-6. Baseline levels of sCTLA-4 did not differ between $\mathrm{APR}+$ and APR- patients and decreased significantly in all from $32-9 \mathrm{ng} /$ $\mathrm{ml}$ to $24-9 \mathrm{ng} / \mathrm{ml}(\mathrm{p}=0.007)$ at $24 \mathrm{hr}, 16-8 \mathrm{ng} / \mathrm{ml}(\mathrm{p}=0.004)$ at $48 \mathrm{hr}$ and $7-6 \mathrm{ng} / \mathrm{ml} \quad(p<0.001)$ at $72 \mathrm{hr}$. Absolute value of sCTLA-4 and mean\% change of SCTLA-4 after ZOL were not statistically different between APR+ and APR- patients. At $72 \mathrm{hr}$, sCTLA-4 decreased by $77 \%(-23 \%)$ in APR+ and by $81 \%(-20 \%)$ in APR- $(p=0.786)$. There were no statistically significant correlations between serum SCTLA-4 levels with any clinical or biochemical parameter of APR.

Conclusion: Contrary to our hypothesis, SCTLA-4 was not related to the occurrence of APR after ZOL. The significance of the substantial decrease of circulating levels of SCTLA-4 after ZOL in all studied patients warrants further investigation.

Disclosure of Interests: Gerolamo Bianchi Consultant for: Alfa-Sigma, Amgen, BMS, Celgene, Medac, UCB, Speakers bureau: Abbvie, Abiogen, Alfa-Sigma, Amgen, BMS, Celgene, Daniele Saverino: None declared, Dario Camellino Consultant for: Janssen-Cilag, Novartis, AbbVie, Sanofi, Paid instructor for: Mylan, Andrea Giusti Grant/research support from: Abiogen Pharma, Consultant for: EffRx, Speakers bureau: Abiogen Pharma Eli Lilly, AMGEN, Erika lervasi: None declared, Giuseppe Girasole: None declared, Socrates Papapoulos Grant/research support from: No in the last 3 years, Consultant for: Amgen, Axsome, Gador, Radius Health, UCB, Speakers bureau: Amgen, UCB

DOI: 10.1136/annrheumdis-2019-eular.6198

\section{FRI0481 MEDIATORS OF BONE METABOLISM (DKK1, OPG SCLEROSTIN AND RANKL) IN A COHORT OF PATIENTS WITH ELDERLY-ONSET ARTHRITIS}

Anahy Brandy-Garcia ${ }^{1}$, Melania Martínez-Morillo ${ }^{1}$, Roxana Coras ${ }^{2}$, Lourdes Mateo Soria', Susana Holgado Pérez ${ }^{1}$, Maria Aparicio Espinar' ${ }^{1}$, Águeda PriorEspañol $^{1}$, Anne Riveros ${ }^{1}$, Clara Sanguesa ${ }^{1}$, Jordi Camins-Fàbregas ${ }^{1}$, Ivette Casafont-Solé ${ }^{1}$, Annika Nack ${ }^{1}$, Alejandro Olive ${ }^{1}$, Monica Guma ${ }^{2}$, Laia Gifre ${ }^{1}$ ${ }^{1}$ Hospital Universitario Germans Trias i Pujol, Rheumatology, Badalona, Spain; ${ }^{2}$ University of California, Departament of Medicine, School of Medicine., San Diego, United States of America

Background: Patients with elderly-onset arthritis have greater comorbidity than young patients, with a higher incidence of osteoporosis (OP), probably mediated by increased bone resorption. However, there are few data on bone metabolism mediators in this population.

Objectives: To analyze bone remodeling mediators (DKK1, sclerostin, osteoprotegerin [OPG], and RANKL) in patients with elderly-onset arthritis and its relationship with bone mineral density.

Methods: Longitudinal observational study that included patients with elderly-onset arthritis (> 65 years) without diagnosis of OP or on antiosteoporotic treatment. Phospho-calcium metabolism, quantification of bone remodeling mediators (ELISA, R\&D systems) and bone densitometry, were determined in all patients at diagnosis and at 12 months. The results were compared with a control group of the same age and sex $(n=14)$. The statistical study was performed using SPSS

Results: We included 73 patients (37F: $36 \mathrm{M}$ ), with a mean age of $75 \pm 7$ years. Most were diagnosed with rheumatoid arthritis (RA) $(n=43)$, followed by polymyalgia rheumatica $(n=16)$ and others $(n=14)$. Fifteen patients were rheumatoid factor (RF) positive and 23 were ACA positive Five patients had erosions at the diagnosis. $88.64 \%$ of patients with RA had an initial DAS28-VSG $>5.1$. Only 3 patients had previous fragility fractures $(2$ vertebral and 1 femur fractures).

At diagnosis, patients with elderly-onset arthritis had higher levels of DKK1 and CTX than the control group, with no statistically significant differences in sclerostin, OPG, and RANKL values (table 1). In addition, DKK1 values were negatively correlated with sclerostin $(r=-0.286$, $\mathrm{p}=0.016)$ and OPG $(\mathrm{r}=-0.276, \mathrm{p}=0.020) .31 .9 \%$ had densitometric OP. We found no significant differences in bone remodeling mediators between patients with/without basal OP.
At 12 months, DAS28-VSG was $<2.6$ in $38.1 \%$. The mean corticosteroid dose was $5.5 \mathrm{mg} /$ day with a cumulative dose of $1630 \pm 426 \mathrm{mg} .45 .8 \%$ received antiosteoporotic treatment (28 patients' bisphosphonates and 5 denosumab). The prevalence of OP at 12 months was $31.3 \%$ and 4 patients had new fractures (4 vertebral and 1 femur fractures). We observed a marked decrease in the values of DKK1 $(-18.89 \%, p<0.001)$ and sclerostin $(-46.76 \%, p<0.001)$ and an increase in OPG $(11.97 \%$, $\mathrm{p}=0.018$ ).

We didn't found relationship between bone metabolim mediators and cumulative corticosteroid dose. There were not differences in terms of diagnosis (RA or PRM), ACPA positivity, activity scores or treatment with bisphosphonates.

Conclusion: Patients with elderly-onset arthritis have higher Dkk1 values than the control group, and this correlate negatively with sclerostin and OPG. The marked decrease in Dkk-1 and sclerostin at 12 months, and the increase in OPG, suggests a role for these mediators in the bone metabolism of this population. It is important to note the high prevalence of $\mathrm{OP}$ in this group of patients.

Table 1. *We excluded patients treated with denosumab. $\uparrow \mathrm{p}<0.005$ with respect to the control group. $\$ p<0.05$ with respect to baseline

\begin{tabular}{|c|c|c|c|}
\hline Variables & $\begin{array}{c}\text { Control } \\
N=14\end{array}$ & $\begin{array}{l}\text { Basal patients } \\
\quad \mathrm{N}=73\end{array}$ & $\begin{array}{c}12 \text { months patients } \\
\mathrm{N}=72\end{array}$ \\
\hline VSG(mm/h) & $14 \pm 10$ & $55 \pm 27 \dagger$ & $27 \pm 18+t$ \\
\hline $\mathrm{PCR}(\mathrm{mg} / \mathrm{L})$ & $3.6 \pm 6.6$ & $38,1 \pm 50,6 \dagger$ & $4,9 \pm 5,5+t$ \\
\hline $\mathrm{HAQ}$ & - & $1,6 \pm 0,75$ & $0,51 \pm 0,57 \ddagger$ \\
\hline $\begin{array}{l}\text { DAS28-VSG(in RA) } \\
\{n=43\}\end{array}$ & - & $6,32 \pm 1,04$ & $3,10 \pm 1,30 \ddagger$ \\
\hline CTX $(\mathrm{ng} / \mathrm{mL})$ & $0,33 \pm 0,18$ & $0,49 \pm 0,19 \dagger$ & $0,26 \pm 0,13 \ddagger$ \\
\hline $\mathrm{OPG}(\mathrm{pg} / \mathrm{ml})$ & $3127 \pm 948$ & $3319 \pm 1134$ & $3647 \pm 1466 \ddagger$ \\
\hline DKK-1 $(\mathrm{pg} / \mathrm{ml})$ & $1558 \pm 555$ & $2740 \pm 1611 \dagger$ & $1516 \pm 985 \ddagger$ \\
\hline Sclerostin(pg/ml) & $1299 \pm 961$ & $1189 \pm 626$ & $515 \pm 333 \dagger$ \\
\hline RANKL(pg/ml) & $122 \pm 184$ & $101 \pm 102$ & - \\
\hline $\begin{array}{l}\text { RANKL indetectable } \mathrm{n} \\
(\%)\end{array}$ & $9(64.3)$ & $16(22.5)$ & $72(100)$ \\
\hline
\end{tabular}

Disclosure of Interests: None declared

DOI: 10.1136/annrheumdis-2019-eular.5305

\section{FRI0482 RISK FACTORS FOR FRAGILITY FRACTURE IN PATIENTS WHO SMOKE: AN OBSERVATIONAL STUDY}

Dominic Beith ${ }^{1}$, Marwan Bukhari ${ }^{2} .{ }^{1}$ Lancaster University, Lancaster Medical School, Lancaster, United Kingdom; ${ }^{2}$ Royal Lancaster Infirmary, Rheumatology, Lancaster, United Kingdom

Background: Smoking is a risk factor for osteoporosis and increases the likelihood of a fragility fracture. It is included in the FRAXTM tool, which is used as an aid for bone mineral density (BMD) referral and as a risk stratification for the propensity of developing a fragility fracture. The additive effect of other risk factors including demographics increasing the risk of fracture has not been explored in a large cohort.

Objectives: To investigate the additive predictors of fracture in patients who have smoking as their only risk for fracture, referred for BMD estimation.

Methods: Patients who were referred for bone mineral density (BMD) estimation in a scanner in the North West of England between June 2004 and October 2015 were included in the analysis. Patients with only smoking as a FRAXTM risk factor were then analysed. All patients have their other risk factors for fracture and demographics recorded at time of scan. All patients with other FRAX'M indications for scanning were excluded including Rheumatoid Arthritis, Excess Alcohol, Steroids, family history of fracture and Secondary Osteoporosis. Patients in the smoking group were divided into those that had experienced a fracture and those that had not before comparing with Chi-squared test for categorical variables and T-test for continuous variables. Univariate and multivariate logistic models were then fitted to examine predictors of fracture in this group.

Results: 35,759 patients were referred for scanning during the period. $4096(11.45 \%)$ were referred with smoking as their only indication for scanning. Mean age at scan was 64.43 (SD 12.38) and 3244 (79\%) of the cohort were females. $1663(40.60 \%)$ had a fracture. Fractures were more prevalent in males with 383 (44.95\%) compared to $1280(39.46 \%)$ in females $(p=<0.05)$.

Univariate predictors shown in the Table 1 below. 
Table 1. Univariate predictors of fracture in the smoking cohort * denotes significant prediction

\begin{tabular}{|c|c|c|c|c|}
\hline Predictor & $\begin{array}{l}\text { Fracture } \\
(n=1663)\end{array}$ & $\begin{array}{l}\text { No Fracture } \\
(n=2433)\end{array}$ & $\begin{array}{l}\text { Odds } \\
\text { ratio }\end{array}$ & $95 \% \mathrm{Cl}$ \\
\hline Age (years) & 66.58 & 62.97 & $1.03^{*}$ & $\begin{array}{r}{[1.02} \\
1.03]\end{array}$ \\
\hline Gender (no. of patients) & $\begin{array}{c}\text { Male }(383) \\
\text { Female (1280) }\end{array}$ & $\begin{array}{c}\text { Male (469) } \\
\text { Female (1964) }\end{array}$ & $0.80^{*}$ & $\begin{array}{r}{[0.69} \\
0.93]\end{array}$ \\
\hline Height $(\mathrm{cm})$ & 162.26 & 162.41 & 1.00 & $\begin{array}{c}{[0.99} \\
1.01]\end{array}$ \\
\hline Weight (kg) & 71.16 & 71.16 & 1.00 & $\begin{array}{r}{[1.00} \\
1.00]\end{array}$ \\
\hline L1-L4 BMD $\left(\mathrm{g} / \mathrm{cm}^{2}\right)$ & 1.04 & 1.10 & $0.19^{*}$ & $\begin{array}{r}{[0.13} \\
0.26]\end{array}$ \\
\hline $\begin{array}{l}\text { Femoral neck BMD (left) }(\mathrm{g} / \\
\left.\mathrm{cm}^{2}\right)\end{array}$ & 0.82 & 0.87 & $0.08^{*}$ & $\begin{array}{r}{[0.05} \\
0.12]\end{array}$ \\
\hline $\begin{array}{l}\text { Total femur BMD (left) }(\mathrm{g} / \\
\mathrm{cm}^{2} \text { ) }\end{array}$ & 0.87 & 0.92 & $0.10^{*}$ & $\begin{array}{r}{[0.07} \\
0.16]\end{array}$ \\
\hline$\%$ Body fat $(\mathrm{g})$ & 308.15 & 299.89 & $1.00^{*}$ & $\begin{array}{r}{[1.00} \\
1.00] \\
\end{array}$ \\
\hline
\end{tabular}

In the multivariate model, the only variables associated with increased fracture risk was increasing age at scan decreased BMD total left and increased percentage body fat. All other factors did not significantly increase fracture risk in this cohort.

Conclusion: Our study suggests that many risk factors are associated with fragility fractures in those with smoking as their only risk factor; the best predictor was age at scan, BMD and gender. The percentage body fat association with increased fracture risk is quite surprising and would need further study. Percentage body fact is not currently included in the FRAX'TM tool.

Disclosure of Interests: Dominic Beith: None declared, Marwan Bukhari Speakers bureau: Bristol-Myers Squib, UCB celltech, Roche/Chugai, Pfizer, Abbvie, Merck, Mennarini, Sanofi-aventis, Eli-Lilly, Janssen and Novartis. DOI: 10.1136/annrheumdis-2019-eular.2453

\section{FRI0483 \\ INTEREST OF A SYSTEMATIC SCREENING OF OSTEOPOROSIS IN HEART TRANSPLANT PATIENTS}

CORALLI Romain ${ }^{1,1}$, Constance Verdonk ${ }^{2}$, Sebastien Ottaviani ${ }^{1}$, Julia Goossens ${ }^{1}$, Lucie Demaria ${ }^{1}$, Elisabeth Palazzo ${ }^{1}$, Richard Dorent ${ }^{2}$, Philippe Dieudé ${ }^{1}$,

Marine Forien'. ' hôpital Bichat, Rheumatology, Paris, France; ${ }^{2}$ hôpital Bichat, Cardiology, Paris, France

Background: Osteoporosis is common among patients with end-stage heart disease. A rapid decrease of bone mineral density (BMD) is usually observed after heart transplantation. Bone loss is probably linked to glucocorticoids and calcineurin inhibitors use and vitamin D deficiency.

Objectives: The aim of this study was to evaluate the interest of a systematic screening of osteoporosis in heart transplant patients.

Methods: We performed a prospective monocentric study including patients, who had of heart transplantation in our hospital, from December 2016 to January 2019.The following parameters were systematically assesses: history of cardiac disease, immunosuppressive therapies, glucocorticoids, previous history of low trauma fracture, known risk factors of osteoporosis, treatment received for bone disease management (calcium, vitamin $\mathrm{D}$ and bisphosphonates). Blood tests with creatinine clearance, calcium and vitamin D levels, were assessed. Bone densitometry and spine radiographs (to search asymptomatic vertebral fractures) were assessed in all patients. Osteoporosis was defined respectively for patients $\geq 50$ years and $<50$ years as a T-score $\leq-2.5$ SD and Z-score $\leq-2$ SD either at lumbar spine (L2-L4), femoral neck or hip.

Results: A total of 42 patients were included $(76.7 \%$ male), mean age was $58.1 \pm 10.6$ years, mean duration after transplantation was $2.6 \pm 3.1$ years. Past or active smoking statues were observed in 26 patients (mean 23.9 pack-years). Calcium, vitamin $\mathrm{D}$ and bisphosphonates were administered in $13(30.9 \%), 10(23.8 \%)$ and one patients, respectively. All patients received prednisone (mean dose: $10.7 \pm 4.9$ per day). Mean lumbar spine BMD was $1.03 \pm 0.25 \mathrm{~g} / \mathrm{cm}^{2}$ and left femoral neck BMD 0.85 $\pm 0.15 \mathrm{~g} / \mathrm{cm}^{2}$. Osteoporosis was observed in $18(45 \%)$ patients. Only one hip fracture was known before heart transplantation. Incidental low trauma fractures after transplantation were diagnosed in 14 patients (33.3\%): 11 patients with vertebral fractures (mean 2 vertebral fractures per patient) including 4 patients with asymptomatic vertebral fractures. Others low trauma fractures were hip fracture, proximal humerus and fibula for one patient each. Mean duration between transplantation and the first low trauma fracture was $7.5 \pm 3.7$ months. Low level of calcemia was found in
20 patients $(47.6 \%)$ and low level of vitamin D $(\leq 30 \mathrm{mg} / \mathrm{l})$ in 32 patients $(76.2 \%)$ associated with secondary hyperparathyroidism in 21 patients $(51.2 \%)$, mean creatinine clearance was $51.7 \pm 19.9 \mathrm{ml} / \mathrm{min}$. After evaluation, specific treatment of osteoporosis was started for 33 patients $(78.6 \%$ ): zoledronic acid $(n=20)$, denosumab $(n=8)$, alendronate $(n=4)$ and teriparatide $(n=1)$.

Conclusion: Systematic screening of osteoporosis seems to be useful in heart transplant patients. Osteoporosis was observed in half of these patients with a high frequency of low trauma fracture after heart transplantation, particularly in the first year.

Disclosure of Interests: None declared

DOI: 10.1136/annrheumdis-2019-eular.7504

\section{FRI0484 RESULTS OF BONE MINERAL DENSITY DURING CELIAC DISEASE: ABOUT 83 CASES}

Cyrine Daldoul, Nejla El Amri, Khadija Baccouch, Hela Zeglaoui, Elyes Bouajina. Farhat Hached Hospital, Rheumatology, Sousse, Tunisia

Background: The prevalence of osteopenia during celiac disease (CD) can range from $38 \%$ to $72 \%$. In fact, it is a pathology that causes bone loss and is associated with a higher fracture risk compared to the general population.

Objectives: The aim of this work is to determine the frequency and factors associated with the decline in bone mineral density in adult subjects with CD.

Methods: This is a retrospective study, over a period of 4 years (from January 2014 to December 2018) and including patients followed for MC who had a measurement of bone mineral density (BMD) by DEXA.

Clinical, anthropometric and densitometric data (BMD at the femoral and vertebral site) were recorded.

The WHO criteria for the definition of osteoporosis and osteopenia have been used.

Results: 83 patients were collected among them 12 were men (sex ratio $=0.16$ ). The average age was 38.2 years old. The average body mass index (BMI) was $21.64 \mathrm{~kg} / \mathrm{m}^{2}$ [13.05-31.9 kg/m²]. Undernutrition (BMI <19 $\mathrm{kg} / \mathrm{m}^{2}$ ) was found in 24 cases. It was associated with hyperthyroidism in 5 cases, autoimmune hepatitis in 1 case and primary amenorrhoea in 2 cases. 2 patients had a history of fragility fracture, and 5 patients had a history of fragility fracture in a first-degree relative.

Osteodensitometry showed low bone mass in 36 cases: osteoporosis in 23 patients $(27.7 \%)$ and osteopenia in 13 cases. Osteoporosis was found in 21 patients: 1 man and 20 women. Mean femoral BMD was $0.887 \mathrm{~g} /$ $\mathrm{cm} 3$ and vertebral BMD was $0.999 \mathrm{~g} / \mathrm{cm} 3$. The mean T-score at the femoral site and the vertebral site were -1.28 SD and -1.26 SD, respectively. No correlation was found between age and BMD and bone status. Comparing patients with a BMI $<19 \mathrm{~kg} / \mathrm{m}^{2}$ to those with a BMI $\geq 19 \mathrm{~kg} /$ $\mathrm{m}^{2}$, BMD at the vertebral site was significantly lower in malnourished subjects $(p=0.01)$. a significant correlation was found between BMI and vertebral BMD $(p=0.000)$

Conclusion: The decline in BMD was observed in third of our patients. It seems to be favored by a low BMI, which is common during CD in relation to the associated malabsorption. Thus, screening for osteoporosis should be advocated early in the course of $C D$.

Disclosure of Interests: None declared

DOI: 10.1136/annrheumdis-2019-eular.8265

\section{FRI0485 TIMED UP AND GO TEST FOR VERTEBRAL FRACTURE PREDICTION}

Cyrine Daldoul ${ }^{1}$, Nejla El Amri ${ }^{1}$, Khadija Baccouch ${ }^{1}$, Amine Kalai $^{2}$, Mohamed Amine Triki ${ }^{3}$, Hela Zeglaoui ${ }^{1}$, Elyes Bouajina ${ }^{1} .{ }^{1}$ Farhat Hached Hospital, Rheumatology, Sousse, Tunisia; ${ }^{2}$ Fattouma Bourguiba Hospital, Rehabilitation, Monastir, Tunisia; ${ }^{3}$ Sahloul Hospital, Orthopaedic Surgery, Sousse, Tunisia

Background: Sarcopenia describes the age related loss of skeletal mus cular mass and function. The development of sarcopenia may confer an increased risk of falls which leads to a potential increase in fracture. The Timed Up and Go (TUG) Test is one of clinical tools used to assess sarcopenia.

Objectives: We hypothesized that slow TUG test performance would predict vertebral fracture (VF) in post-menopausal women independently of bone mineral density (BMD) and other risk factors.

Methods: This is a cross sectional study enrolled from September 2018 to December 2018, including post-menopausal women referred to rheumatology department for measure of BMD. All subjects underwent dual energy X-ray absorptiometry (DeXA) and physical performance tests 